\title{
Bioleaching of nickel from equilibrium fluid catalytic cracking catalysts
}

\author{
Oguz Bayraktar \\ Department of Chemical Engineering, Bioreaction Engineering Laboratory, Izmir Institute of Technology, Gülbahce \\ Köyü, 35437 Urla-Izmir, Turkey; Tel.: +90 232 750-6287,Fax: + 90232 750-6196, E-mail: oguzbayraktar@iyte.edu.tr
}

Keywords: Aspergillus niger, bioleaching, FCC, fluidized catalytic cracking catalyst, nickel

\begin{abstract}
Summary
This study investigates the possibility of reusing metal-contaminated equilibrium fluid catalytic cracking (FCC) catalyst after bioleaching. Leaching with Aspergillus niger culture was found to be more effective in the mobilization of nickel from the catalyst particles compared to chemical leaching with citric acid. Bioleaching achieved $32 \%$ nickel removal whereas chemical leaching achieved only $21 \%$ nickel removal from catalyst particles. The enhanced nickel removal from the catalysts in the presence of $A$. niger culture was attributed to the biosorption ability of the fungal mycelium and to the higher local concentration of citric acid on the catalyst surface. It was found that $9 \%$ of solubilized nickel in the liquid medium was biosorbed to fungal biomass. After nickel leaching with A. niger culture, the hydrogen-to-methane molar ratio and coke yield, which are the measures of dehydrogenation reactions catalysed by nickel during cracking reactions, decreased significantly.
\end{abstract}

\section{Introduction}

The fluid catalytic cracking (FCC) process is used for the conversion of relatively high-temperature boiling hydrocarbons to lower temperature-boiling hydrocarbons in the heating oil and gasoline range. During the cracking process, nickel- and vanadium-containing porphyrins and porphyrin-like complexes from the hydrocarbon feed decompose, leaving metal contaminants on the FCC catalyst surface. These metals increase the production of coke, hydrogen, and light gases formation at the expense of the highly desired gasoline (Cimbalo et al. 1972). After reaction in the fluidized catalytic cracking unit (FCCU) spent catalysts are removed from the unit and replaced by fresh catalysts in order to maintain the desired catalytic activity. These spent catalysts are called equilibrium catalysts (ECat). Spent FCC catalysts constitute a significant portion of the solid wastes generated in the petrochemical industry. Furimsky (1996) pointed out that on a world scale about 400,000 tons of spent catalysts from FCCU are produced annually. Spent catalysts can be used as secondary raw materials, or disposed of in land farming or land filling (Hsu et al. 1996; Su et al. 2001). Since catalysts contain contaminants picked up in the processes for which they were used, there has been an increasing concern about the land disposal of spent catalysts. The ability to restore catalyst activity by using an appropriate demetallization process would greatly reduce toxic waste. Demetallization processes involve the physical removal of the metal contaminants from the catalysts. The process called 'Demet' is claimed to reduce both fresh catalyst addition and spent catalyst disposal when used with any FCC catalyst (Yoo 1998). In this process, first the metals on the catalyst are oxidized, sulphided and chlorinated in the reactor section. Then, the nickel and sodium chlorides are washed from the catalyst. Since chlorination techniques are destructive to zeolitecontaining catalyst, they have received less and less consideration in commercial use.

Biotechnological removal of such metal contaminants from used catalysts has not received enough attention. Although the microbial leaching of metals became successful by using chemolithoautotrophic bacteria to solubilize metals from materials containing sulphide and/or ferrous compounds (Sukla et al. 1993; Krebs et al. 1997), only Myerson \& Ernst (1985) mentioned the removal of metal impurities from spent catalysts. The use of fungi was thought to be an interesting alternative (Bosecker 1997) since fungi could solubilize metals from ores by the excretion of organic acids. Aspergillus niger and Penicillium simplicissimum are the two widely used species for bioleaching of metals from ores. Bioleaching of valuable elements ( $\mathrm{Al}, \mathrm{Co}, \mathrm{Cu}, \mathrm{Ni}$ ) from ores using micro-fungal species like Penicillia or Aspergilli has been investigated earlier (Sukla et al. 1993). In general a $\mathrm{pH}$ range between 2 and 8 , a temperature range between 20 and $40{ }^{\circ} \mathrm{C}$, and a high resistance to heavy metals are characteristics of leaching processes with fungi (Burgstaller \& Schinner 1993). Fungi have been used 
in the past for the leaching of carbonaceous low-grade ores and mining wastes (Wenberg et al, 1971), industrial filter dusts (Burgstaller et al. 1992), electronic scrap (Brandl et al. 2001) and coal wastes (Scott et al. 1986).

The main objective of this research was the elimination of nickel from equilibrium FCC catalysts so as to recover catalyst activity partially. This study focuses on nickel removal from the metal-contaminated FCC catalysts using $A$. niger culture. Citric acid constituted the major acid produced from A. niger strain. For this reason citric acid was used in chemical leaching experiments to mimic the chemical action of $A$. niger culture in order to understand the difference between chemical leaching with citric acid and bioleaching. Besides, the effectiveness of citric acid in solubilizing nickel from ores was reported earlier in the literature (Valix et al. 2001). The equilibrium catalysts being subjected to bioleaching and chemical leaching with citric acid were used in the catalytic cracking of gas oil. During the cracking reactions the hydrogen and coke produced by nickelcatalysed dehydrogenation reactions were measured to compare the effects of both bioleaching and chemical leaching on nickel removal from the FCC catalyst.

\section{Materials and methods}

\section{Catalyst samples}

Commercial equilibrium FCC catalysts supplied by Marathon-Ashland Oil Inc., Ashland (USA) were used in bioleaching and cracking experiments. They are named ECat-LOW, ECat-INT and ECat-HIGH based on their nickel concentration. The concentration of nickel in Ecat-LOW, ECat-INT and ECat-HIGH were 300 nickel 900 and $2600 \mathrm{mg} \mathrm{kg}^{-1}$ respectively.

\section{Bioleaching and chemical leaching}

A lyophilized culture of $A$. niger from Presque Isle Cultures (Erie, USA) was used, in all bioleaching experiments. First, the lyophilized culture was revived properly and growth of the fungus was observed and monitored by measuring the $\mathrm{pH}$ for 21 days. The organism was cultivated on a sucrose medium in baffled 250-ml Erlenmeyer flasks Wid incubated at $30{ }^{\circ} \mathrm{C}$ on an orbital shaker at $150 \mathrm{rev} \mathrm{min}^{-1}$. The growth medium contained (in $\mathrm{g} \mathrm{l}^{-1}$ ) sucrose (100), $\mathrm{NaNO}_{3}$ (1.5), $\mathrm{KH}_{2} \mathrm{PO}_{4}(0.5), \mathrm{MgSO}_{4} \cdot 7 \mathrm{H}_{2} \mathrm{O}(0.025), \mathrm{KCl}(0.025)$, and yeast extract (1.6). The medium was sterilized by autoclaving at $120{ }^{\circ} \mathrm{C}$ to reduce the interference from other microorganisms. The fungal culture was grown in the presence of different amounts of ECat-HIGH catalyst. The pulp densities used in the inhibition experiments were $5 \mathrm{l}^{-1}$ and $10 \mathrm{~g} \mathrm{l}^{-1}$. Inoculation was conducted by adding the fungal spores to the mixture of catalyst and growth medium. Fungal growth in the presence of equilibrium catalysts sample was monitored by measuring the $\mathrm{pH}$ of the medium for 21 days. In all cases the initial $\mathrm{pH}$ of the growth medium was adjusted to a value of 6.5. All of the bioleaching experiments were conducted at a pulp density of $5 \mathrm{~g} \mathrm{l}^{-1}$. The inhibition and control (only culture medium without fungi) experiments were conducted using only the highly nickelcontaminated (ECat-HIGH) catalyst sample. However, both bioleaching and chemical leaching with citric acid experiments were carried out with three catalyst samples named ECat-LOW, ECat-INT and ECat-HIGH based on their nickel concentration.

Controlled chemical leaching experiments with citric acid were also conducted. Citric acid was used because of its ability for solubilizing nickel. This acid also constitutes the major acid produced from the fungus strains. Chemical leaching of the spent FCC catalyst was achieved by adding a solution $39 \mathrm{~g}$ citric acid $1^{-1}$ to equilibrium catalyst particles. This concentration value was selected since this was the highest citric acid concentration in the A. niger culture at the end of the 21 day incubation period. The slurry mixture was kept at $30^{\circ} \mathrm{C}$ on an orbital shaker $\left(150 \mathrm{rev} \mathrm{min}^{-1}\right)$ and leaching was carried out for a period of 21 days. In both chemical and bioleaching experiments, catalyst samples were taken at the end of the incubation period, and were filtered and then washed with distilled water.

The amount of nickel on the catalyst particles was determined using inductively coupled plasma-atomic absorption spectroscopy (ICP-AES) with standard procedures. $0.5 \mathrm{~g}$ catalyst sample was weighed into a platinum dish and approximately $20 \mathrm{ml}$ of deionized water was added. After slowly adding $3 \mathrm{ml}$ of concentrated hydrofluoric acid, $5 \mathrm{ml}$ concentrated sulphuric acid and $1 \mathrm{ml}$ concentrated nitric acid were subsequently added to the platinum dish. Volatile compounds were fumed off until the residue was slightly moist with sulphuric acid. After cooling down, approximately $40 \mathrm{ml}$ of deionized water and $15 \mathrm{ml}$ of hydrochloric acid were added to the platinum dish, wich was warmed until the sample was completely dissolved. The solution was tranferred into a $100 \mathrm{ml}$ volumetric flask and diluted with appropriate amount of deionized water. In a second platinum dish an analogous mixture of deionized water, hydrofluoric acid, sulphuric acid and nitric acid was fumed off and taken up with hydrochloric acid. The solution was transferred into a $100 \mathrm{ml}$ volumetric flask. After appropriate dilution with deionized water it was used as a blank sample. Similarly, acid digestion was used using nitric acid in combination with perchloric acid to determine nickel in the biomass sample.

The amount of citric acid produced by $A$. niger cultures at the end of 21 days was measured by a spectrophotometric method (Marier \& Boulet 1958).

\section{Microactivity test (MAT) evaluation}

MAT measurements of catalyst activity were performed according to the procedures of ASTM D-3907 using sour imported heavy gas oil (Davison Chemical Co.) feed. The MAT measurements for catalyst samples 
named ECat-LOW, ECat-INT and ECat-HIGH based on their nickel concentration were carried out before and after bioleaching experiments. The MAT unit was manufactured by Industrial Automated Systems (Parlin, New Jersey). The microactivity test unit consists of a furnace for maintaining constant cracking temperature $\left(500{ }^{\circ} \mathrm{C}\right)$, a syringe pump whose speed can be varied to inject the cracking feed, a liquid product receiver and a gas collection vessel. Liquid products were condensed at the exit of the reactor by using an ice-water mixture. Product gases were collected by downward displacement of water. To achieve different conversions the reaction severity was varied by changing the catalyst-to-oil ratio $(\mathrm{C} / \mathrm{O})$ where $\mathrm{C} / \mathrm{O}$ ratio is defined as the amount of catalyst divided by the total amount of feed. This ratio was changed by changing the amount of feed while keeping the catalyst amount constant at $5 \mathrm{~g}$. $\mathrm{C} / \mathrm{O}$ ratios of 3,5 , and 8 were used in the cracking experiments. The distribution of gaseous products was analysed by using a Varian 3600 gas chromatograph. The $\mathrm{H}_{2}, \mathrm{C}_{1}, \mathrm{C}_{2}, \mathrm{C}_{3}, \mathrm{C}_{4}$, and $\mathrm{C}_{5}^{+}$lumps were determined quantitatively. The liquid products, after weighing, were dissolved in $\mathrm{CS}_{2}$ solvent and analysed by GC simulated distillation. The D2887 simulated distillation method was used to determine the percentage of the liquid products boiling in the range of gasoline (IBP - 421 F), light cycle oil, LCO (421-640 F), and heavy cycle oil, HCO (640 F and above). A Supelco Petrocol B packed column installed in a Varain $3400 \mathrm{GC}$ was used. Using this method, the conversion as defined by ASTM 3907 was calculated. The yields were calculated as weight percent of reactant. The fractions of gasoline, LCO and HCO were determined by the cut-off points at 421 and $640 \mathrm{~F}$. Conversion was defined as $100 \mathrm{wt} \% \mathrm{ff}$ (LCO, wt $\% \mathrm{ff}+\mathrm{HCO}$, $w t \% \mathrm{ff})$. The amount of coke on the spent catalyst was determined by temperature-programmed oxidation (Bayraktar \& Kugler 2003).

In this study, all experiments were performed at least three times and average values were taken as data points.

\section{Results and discussion}

Depostion of metal contaminants (e.g., nickel, vanadium and iron) on the catalyst causes a decrease in catalyst activity. Both coke and hydrogen productions increase at the expense of gasoline. The negative effect of metal contaminants on the yields can be seen from Table 1. Data presented in Table 1 were obtained at a constant MAT conversion of $50 \%$. MAT conversion can be defined as percentage of the feed converted to gas, gasoline and coke during catalytic cracking reactions. The yields of valuable products, gasoline and LCO, decreased whereas coke yield increased when the nickel content on the cracking catalyst increased from $300 \mathrm{mg} \mathrm{kg}^{-1}$ (ECat-LOW) to $2600 \mathrm{mg} \mathrm{kg}^{-1}$ (ECatHIGH). With increasing nickel content on the catalyst, gasoline yield decreased from $38.43 \%$ (untreated ECatLOW) to $34.47 \%$ (untreated ECat-HIGH). Similarly, LCO yield decreased from 30.87 to $28.74 \%$. On the other hand, coke yield increased significantly from 2.73 to $7.15 \%$. Studies for deposition of these metals on the catalyst showed that nickel was in general homogeneously distributed throughout the catalyst surface (Kugler \& Leta 1988). Nickel was found to be primarily responsible for promoting the dehydrogenation activity which produced coke and gaseous products, in particular, hydrogen and methane at the expense of desired liquid products (Venuto \& Habib 1979). $\mathrm{H}_{2}$ yields from MAT experiments have usually been reported by using hydrogen-to-methane $\left(\mathrm{H}_{2} / \mathrm{CH}_{4}\right)$ molar ratio. Hydrogen production was found to be very sensitive to catalyst metal contamination (Venuto \& Habib 1979). At low catalyst metals level $\left(<1000 \mathrm{mg} \mathrm{kg}^{-1}\right) \mathrm{H}_{2} / \mathrm{CH}_{4}$ ratios of less than 1.0 were found to be typical. At metals level of $1000-1500 \mathrm{mg} \mathrm{kg}^{-1}$, which is the normal level for many FCC units, $\mathrm{H}_{2} / \mathrm{CH}_{4}$ ratios of $1-2$ were found to be typical. For the case of severe metals contamination above $5000 \mathrm{mg} \mathrm{kg}^{-1}, \mathrm{H}_{2} / \mathrm{CH}_{4}$ ratios of 10 or higher would be typical (Venuto \& Habib 1979). As seen from Figure 1, the $\mathrm{H}_{2} / \mathrm{CH}_{4}$ molar ratio was very sensitive to

Table 1. Comparison of yields at 50\% MAT conversion and nickel recoveries after chemical leaching with citric acid and leaching with Aspergillus niger culture.

\begin{tabular}{|c|c|c|c|c|c|c|c|c|}
\hline \multirow[t]{2}{*}{ Catalyst } & \multirow[t]{2}{*}{ Pretreatment } & \multicolumn{7}{|c|}{$\begin{array}{l}\text { Yields } \\
\text { wt } \%\end{array}$} \\
\hline & & Gas & Gasoline & $\mathrm{LCO}$ & $\mathrm{HCO}$ & Coke & $\mathrm{H}_{2} / \mathrm{CH}_{4}$ & Ni recovery $(\%)$ \\
\hline \multirow[t]{3}{*}{ ECat-LOW } & Untreated & 8.84 & 38.43 & 30.87 & 19.87 & $2.73 \pm 0.10$ & $1.12 \pm 0.15$ & - \\
\hline & Leached with citric acid & 8.64 & 38.63 & 30.67 & 20.10 & $2.80 \pm 0.07$ & $1.10 \pm 0.18$ & $9 \pm 0.9$ \\
\hline & Leached with fungi & 8.80 & 38.60 & 30.35 & 19.70 & $2.60 \pm 0.15$ & $0.96 \pm 0.08$ & $16 \pm 1.5$ \\
\hline \multirow[t]{3}{*}{ ECat-INT } & Untreated & 8.74 & 37.10 & 29.32 & 21.15 & $4.05 \pm 0.21$ & $3.10 \pm 0.12$ & - \\
\hline & Leached with citric acid & 8.70 & 37.20 & 29.52 & 20.70 & $3.78 \pm 0.10$ & $2.25 \pm 0.10$ & $12 \pm 1.3$ \\
\hline & Leached with fungi & 8.62 & 37.65 & 30.08 & 20.45 & $3.25 \pm 0.16$ & $1.95 \pm 0.15$ & $26 \pm 2.0$ \\
\hline \multirow[t]{3}{*}{ ECat-HIGH } & Untreated & 8.61 & 34.47 & 28.74 & 21.26 & $7.15 \pm 0.18$ & $7.80 \pm 0.23$ & - \\
\hline & Leached with citric acid & 8.55 & 34.67 & 27.85 & 23.33 & $6.65 \pm 0.12$ & $6.50 \pm 0.31$ & $21 \pm 1.3$ \\
\hline & Leached with fungi & 9.12 & 35.10 & 27.75 & 22.25 & $5.35 \pm 0.09$ & $4.80 \pm 0.20$ & $32 \pm 1.0$ \\
\hline ECat-HIGH & $\begin{array}{l}\text { Treated with culture } \\
\text { medium without fungi }\end{array}$ & 8.70 & 33.95 & 28.54 & 20.85 & $7.35 \pm 0.20$ & $7.65 \pm 0.33$ & $2.7 \pm 0.5$ \\
\hline
\end{tabular}


catalyst metal contamination. When the metals on the catalyst increased, this ratio also increased. In this study, the $\mathrm{H}_{2} / \mathrm{CH}_{4}$ molar ratios were found to be $1.1,3.1$ and 7.8 for ECat-LOW, ECat-INT and ECat-HIGH, respectively, at a constant MAT conversion of $50 \%$. These values were the clear indication of the increase in hydrogen yield with increasing metals concentration on the equilibrium catalysts.

Before performing bioleaching experiments, A. niger cultures were grown in the absence and presence of ECat-HIGH catalyst samples. Organic acid production by fungi was monitored by measuring total acidity of the medium. The decrease in medium $\mathrm{pH}$ was mainly caused by citric acid produced by fungi. Oxalic acid $\left(0.26 \mathrm{~g} \mathrm{l}^{-1}\right)$ production was not significant. Figure 1 shows the profiles of $\mathrm{pH}$ during the growth of $A$. niger in the presence of different amounts of ECat-HIGH catalyst samples. It was clear that if the amount of catalyst was increased, the acid production or metabolic activities of A. niger cells was inhibited. When there was no catalyst in the growth medium, citric acid concentration was measured as $39 \mathrm{~g} \mathrm{l}^{-1}$ and the $\mathrm{pH}$ of the medium decreased to 2.1 at the end of the 21-day incubation. At $5 \mathrm{~g} \mathrm{l}^{-1}$ solid concentration acid production was affected less and the $\mathrm{pH}$ of the medium decreased to 3 . At $10 \mathrm{~g} \mathrm{l}^{-1}$ solid concentrations, acid production was affected significantly and the $\mathrm{pH}$ of medium decreased only up to 4 . Most of the $\mathrm{pH}$ change occurred within the first 4-5 days of incubation period.

Data presented in Table 1 shows how the $\mathrm{H}_{2} / \mathrm{CH}_{4}$ molar ratio and coke yield were affected by both bioleaching and chemical leaching with citric acid. In control experiments some ECat-HIGH catalyst samples were not subjected to any treatment and some ECatHIGH samples were subjected to culture medium in the absence of microorganism prior to catalytic cracking reactions. Some ECat-HIGH samples were subjected to fungal bioleaching and chemical leaching with citric acid. Control experiments with culture medium without microorganism were performed only for Ecat-HIGH catalyst sample. After citric acid leaching and bioleaching treatments, $\mathrm{H}_{2} / \mathrm{CH}_{4}$ molar ratio and coke yield

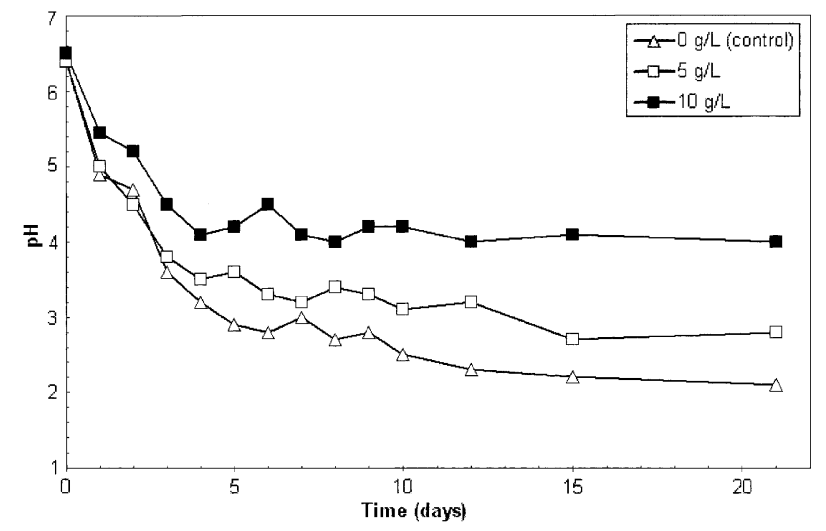

Figure 1. pH profiles of Aspergillus niger cultures grown on different concentration of metal-contaminated equilibrium FCC catalysts. decreased compared to the control experiments for all catalyst samples. The decrease in $\mathrm{H}_{2} / \mathrm{CH}_{4}$ molar ratio and coke yield after bioleaching was more significant compared to chemical leaching with citric acid. Decreases of 7 and $25 \%$ in the coke yields were observed after the ECat-HIGH catalysts were subjected to chemical leaching and bioleaching, respectively. Similarly, 17 and $38 \%$ decrease in $\mathrm{H}_{2} / \mathrm{CH}_{4}$ molar ratios were observed for chemical leaching and bioleaching, respectively. The effect of bioleaching and chemical leaching with citric acid was not very significant for ECat-LOW and ECat-INT catalyst. This could be attributed to the relatively lower nickel removal from ECat-LOW and ECat-INT catalysts compared to ECat-HIGH catalysts.

Since the citric acid concentration corresponding to the concentration obtained at the end of 21-day incubation period of $A$. niger culture was used in the chemical leaching experiments the catalyst particles were subjected to higher levels of citric acid for a longer period of time compared to bioleaching experiments. Therefore after chemical leaching higher or closer nickel recoveries were expected compared to bioleaching. However in bioleaching experiments nickel recovery was greater than those obtained from the chemical leaching tests. These results suggested that the bioleaching process could not be explained merely by the leaching effect of citric acid produced by the fungi. Fungi appeared to participate in the leaching process or citric acid appeared to be used more effectively in the presence of the fungus. Similar observations were made by other researchers (Alibhai et al. 1993; Kar et al. 1995; Castro et al. 2000; Valix et al. 2001). Kar et al. (1995) attributed the enhanced leaching of nickel from lateritic ore to a higher local concentration of the bioacids formed in the presence of fungus than in fungusfree spent medium. On extended incubation, some researchers found that the fungal mycelium bound some of the solubilized nickel (Alibhai et al. 1993, Tzeferlis et al. 1994, Kar et al. 1995). Removal of heavy metals using the fungus $A$. niger was studied in detail and fungal microorganisms could up take nickel intracellularly (Kapoor \& Viraraghavan 1997). Live A. niger biomass was found to be more effective in the removal of nickel than dead A. niger biomass (Kapoor et al. 1999).

Table 1 presents the recovery of nickel from equilibrium catalysts after bioleaching and chemical leaching with citric acid. The nickel recoveries from all catalysts after bioleaching were found to be significantly higher than those after chemical leaching with citric acid (see Table 1). This study showed that bioleaching removed $32 \%$ of nickel whereas chemical leaching removed $21 \%$ of nickel from the ECat-HIGH catalyst sample. For example, after bioleaching $1765 \mathrm{mg} \mathrm{kg}^{-1}$ nickel was determined on the ECat-HIGH catalyst particles by ICP-AES. This means that $32 \%$ of nickel $\left(835 \mathrm{mg} \mathrm{kg}^{-1}\right)$ was solubilized and removed from the ECat-HIGH catalyst particles. At the end of 21 day of bioleaching $758 \mathrm{mg} \mathrm{kg}^{-1}$ nickel was found to be in the liquid 
medium. Material balance for nickel revealed that $77 \mathrm{mg} \mathrm{kg}^{-1}$ nickel could be bound by the fungal mycelium. Nickel concentration of $77 \mathrm{mg} \mathrm{kg}^{-1}$ made up the $9 \%$ of the solubilized nickel from the ECat-HIGH catalyst particles. These experiments were repeated three times and $9 \pm 2 \%$ of solubilized nickel was found to be biosorbed by the fungal biomass. It was clear that biosorption of nickel by fungus played an important role in the enhancement of nickel leaching from the catalyst particles. Probably the attachment of fungi to the surface of catalyst particles caused the increase in the local acid concentration on the catalyst surface. The higher local acid concentration might enhance the solubilization of nickel deposited on the surface of catalysts. Some of the solubilized nickel can be biosorbed by the fungi, which is in close contact with the catalyst particles. Leaching with fungal microorganisms is based on the complexation of metals by the excreted organic acids and bioaccumulation of metals by the organism's mycelium. Although citric acid is an important leaching agent in the extraction of nickel from equilibrium catalyst particles, biosorption of nickel by fungal mycelium should not be under-estimated. Over longer incubation periods, both biosorption and citric acid leaching act together to give better extraction of nickel from catalyst particles compared to leaching with citric acid alone. Repetition of the bioleaching process would increase the nickel recovery from the catalysts, but this would make the process even slower and more expensive compared to a single-step bioleaching process. In short, bioleaching of contaminant metals from catalysts to increase their activities is far from becoming a commercially competitive largescale process. The main limitations are slow kinetics of the process, requirement for expensive growth media, and difficulties in maintaining sterile conditions.

\section{Acknowledgements}

Support from the West Virginia University Department of Chemical Engineering and Izmir Institute of Technology is gratefully acknowledged. We express our thanks to Mr Howard F. Moore, Marathon-Ashland Petroleum, Ashland (USA), for supplying the equilibrium catalysts used in this study.

\section{References}

Alibhai, K., Dudeney, A.W.L. \& Leak, D.J. 1993 Bioleaching and bioprecipitation of nickel and iron from laterites. FEMS Microbiology Review 11, 87-96.

Bayraktar, O. \& Kugler, E.L. 2003 Coke contentent of spent commercial fluid catalytic cracking (FCC) catalysts: determination by temperature-programmed oxidation. Journal of Thermal Analysis and Calorimetry 71, 767-874.

Bosecker, K. 1997 Bioleaching: metal solubilization by microorganisms. FEMS Microbiology Reviews 20, 591-604.

Brandl, H., Bosshard, R. \& Wegmann, M. 2001 Computer-munching microbes: metal leaching from electronic scrap by bacteria and fungi. Hydrometallurgy 59, 319-326.

Burgstaller, W. \& Schinner, F. 1993 Leaching of metals with fungi. Journal of Biotechnology 27, 91-116.

Burgstaller, W., Strasser, H., Wobking, H. \& Schinner, F. 1992 Solubilization of zinc oxide from filter dust with Penicillium simplicissimum: bioreactor leaching and stoichiometry. Enviromental Science and Technology 26, 340-346.

Castro, I.M., Fietto, J.L.R., Vieira, R.X., Tropia, M.J.M., Campos, L.M.M., Paniago, E.B. \& Brandao, R.L. 2000 Bioleaching of zinc and nickel from silicates using Aspergillus niger cultures. Hydrometallurgy 57, 39-49.

Cimbalo, R.N., Foster, R.L. \& Wachtel, S.J. 1972 Deposited metals poison FCC catalyst. Oil and Gas Journal 70, 112-122.

Furimsky, E. 1996 Review of spent refinery catalysts: environment, safety and utilization. Catalysis Today 30, 223-286.

Hsu, W., Chang, H., Hwang, C \& Liao, C. 1996 Utilization of ceramics products made from waste. Ceramics, 15, 20-35.

Kapoor, A. \& Viraraghavan, T. 1997 Heavy metal biosorption sites in Aspergillus niger. Bioresource Technology, 61, 221-227.

Kapoor, A., Viraraghavan, T . \& Cullimore, D.R. 1999 Removal of heavy metals using the fungus Aspergillus niger. Bioresource Technology, 70, 95-104.

Kar, R.N., Sukla, L.B. \& Panchanadikar, V.V. 1995 Extraction of cobalt and nickel from lateritic nickel ore using Rhizopus arrhizus. In Biohydrometallurgical Processing, eds. Vargas, T., Jerez, C.A. \& Wiertz, J.V., Vol. 1. pp. 417-424. Santiago: University of Chile. ISBN.

Krebs, W., Brombacher, C., Bosshard, P.P., Bachofen, R. \& Brandl, H. 1997 Microbial recovery of metals from solids. FEMS Microbiology Reviews 20, 605-617.

Kugler, E.L. \& Leta, D.P. 1988 Nickel and vanadium on equilibrium cracking catalysts by imaging secondary ion mass spectrometry. Journal of Catalysis 109, 387-395.

Marier, J.R. \& Boulet, M. 1958 Direct determination of citric acid in milk with an improved pyridine-actetic anhydride method. Journal of Dairy Science 41, 1683-1692.

Myerson, A.S. \& Ernst, W.R. 1985 Removal of inorganic contaminants from catalysts. US Patent 4559313.

Scott, C.D., Strandberg, G.W. \& Lewis, S.N. 1986 Microbial solubilization of coal. Biotechnology Progress 13, 131-139.

Su, N., Chen, Z.-H. \& Fang, H.-Y. 2001 Reuse of spent catalyst as fine aggregate in cement mortar. Cement and Concrete Composites 23, 111-118.

Sukla, L.B., Panchanadikar, V.V. \& Kar, R.N. 1993 Microbial leaching of lateritic nickel ore. World Journal of Microbiology and Biotechnology 9, 255-257.

Tzeferis, P.G., Agatzini, S. \& Nerantzis, E.T. 1994 Mineral leaching of non-sulphide nickel ores using heterotrophic micro-organisms. Letters in Applied Microbiology 18, 209-213.

Wenberg, G.M., Erbisch, F.H. \& Volin, M.E. 1971 Leaching of copper by fungi, Mining Engineering 23, 207-212.

Valix, M., Usai, F. \& Malik, R. 2001 Fungal bioleaching of low-grade laterite ores. Minerals Engnieering 14, 197-203.

Venuto, P.B. \& Habib, E.T. 1979 Fluid Catalytic Cracking with Zeolite Catalysts. New York: Marcel Dekker Inc., ISBN 0824777824.

Yoo, J.S. 1998 Metal recovery and rejuvenation of metal-loaded spent catalysts. Catalysis Today 44, 27-46. 